\title{
DEVELOPMENT OF COMPOUND FEED RECIPES FOR GEESE AND DETERMINATION OF THEIR QUALITY
}

Abstract

The article describes that goose farming is an important source of increasing poultry production and expanding the range of poultry products. In Ukraine, the goose breeding business is promising, profitable and underdeveloped, with low competition. The profitability of geese breeding is about 75\%. In addition, goose farming is one of the possible ways to solve the problem of animal protein deficiency in the world.

The high-quality calculation of recipes is a necessary part of efficient production and use of finished products at the present stage of the feed industry development.

Optimization of compound feed recipes determines its composition and takes into account the impact of certain feed components on the physiology, health, growth and productivity of animals. Recipe calculation programs occupy a key place in the technological chain of animal husbandry production, combining producer and products consumer.

The quality of the final product and the compliance of the calculated indicators of nutritional value with the actual depend on the accuracy of the recipes calculation and take into account all the destabilizing factors in the technological production process. Thanks to modern software optimization of recipes, it becomes possible not only to make a diet with available raw materials that is optimal in quality and cost, but also to assess the feasibility of introducing a particular additive, both from a biological and economic point of view.

It is proven that geese must receive high quality and balanced feed by all indicators for the normal development and realization of genetic potential. Therefore, the urgent task is to develop recipes for high-quality geese feed using domestic available raw materials.

With the help of the software package "Korm Optima Expert" we have developed complete feed recipes for parent flock geese aged 0... 3 weeks (starter), 4.. 8 weeks (grower), 9.. 26 weeks (finisher), older 27 weeks (breeder), and recipes for broiler type geese aged 0 ... 4 weeks (starter) and older 5 weeks (finisher). The program includes the principle of calculating recipes at the minimum cost, taking into account the limitations of the input of each component and the nutritional value of the finished product using linear programming formulas.

Experimental samples of starter, grower, finisher and breeder were made in accordance with the developed recipes of complete feed for parent flock geese. Physical properties and chemical composition were studied in the experimental samples. It is established that the experimental samples of starter, grower, finisher and breeder are characterized by satisfactory physical properties and comply with regulatory and technical documentation. They are balanced in content of nutrients and biologically active substances and meet the physiological needs and feeding standards of the parent flock geese.

Key words: compound feeds for geese, physical properties, chemical composition, amino acid composition, nutritional indicators.

\section{Introduction}

Compound feed products play a major role in the development of industrial animal husbandry and poultry farming in Ukraine. The development of feed production is an urgent task, because meat and meat products account for $24-28 \%$ in the diet of Ukraine population $[1,2]$.

The most important branch of the agroindustrial complex is poultry, which has not only industrial but also social significance for the country's economy and affects the state of its food security. The consumer value of poultry is determined by its ability to supply valuable food products of domestic production. In conditions of declining incomes of Ukraine population, there is a need to provide the body with quality animal husbandry products at affordable prices, including diet eggs and meat.
Expanding the range of products, improving its quality until the so-called functional foods with specified properties is of great importance in increasing poultry products production in terms of improving the welfare of the population and increasing the number of citizens with relatively high purchasing power [3].

Goose farming is an important source of increasing poultry production and expanding the range of poultry products. In Ukraine, the goose breeding business is promising, profitable and underdeveloped, with low competition. The profitability of geese breeding is about $75 \%$. In addition, goose farming is one of the possible ways to solve the problem of animal protein deficiency in the world.

The reasons of the attractiveness of breeding and rearing geese are:

$\checkmark$ unpretentiousness of the poultry to the keeping 
Table 1 - Nutritional value and cost of feed components for geese [7]

\begin{tabular}{|c|c|c|c|c|c|c|c|c|c|c|c|c|c|c|}
\hline \multirow[t]{2}{*}{ Component } & \multirow{2}{*}{\begin{tabular}{|c|} 
Metabolizable \\
energy, \\
KCal / 100g \\
\end{tabular}} & \multicolumn{12}{|c|}{ The mass fraction, $\%$} & \multirow{2}{*}{$\begin{array}{c}\text { Price, UAH/kg } \\
\text { (september 2020) }\end{array}$} \\
\hline & & moisture & crude protein & crude fat & linoleic acid & crude fiber & $\mathrm{Ca}$ & $\mathrm{P}$ & $\mathrm{Na}$ & lysine & methionine & threonine & tryptophan & \\
\hline Corn & 330 & 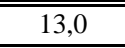 & 8,5 & 4,00 & 1,80 & 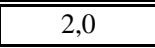 & 0,02 & 0,25 & 0,03 & 0,26 & 0,18 & 0,30 & 0,07 & 5,40 \\
\hline $\begin{array}{l}\text { Oats without husk } \\
\end{array}$ & 287 & 12,0 & $\overline{12,2}$ & 4,70 & 1,63 & 2,2 & 0,10 & $\begin{array}{ll}0,30 \\
\end{array}$ & 0,03 & 0,50 & 0,20 & $\overline{0,40}$ & 0,17 & 6,50 \\
\hline Triticale & 285 & $\overline{\overline{13,0}}$ & $\overline{12,1}$ & $\overline{11,50}$ & $\overline{0,60}$ & $2, \bar{c}$ & $\overline{0,06}$ & 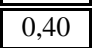 & 0,03 & $\overline{0,38}$ & $\overline{0,20}$ & $\overline{\overline{0,36}}$ & $\overline{0,12}$ & 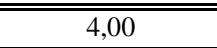 \\
\hline Sorghum & 295 & 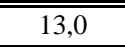 & 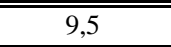 & 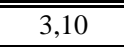 & 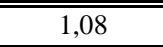 & 3,0 & 0,05 & (0,28 & 0,03 & 0,22 & 0,17 & 0,32 & 0,12 & 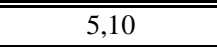 \\
\hline $\begin{array}{ll}\text { Rye } \\
\end{array}$ & 238 & 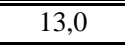 & 8,2 & 2,00 & $\overline{0,78}$ & 2,40 & 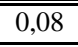 & 0,30 & 0,02 & 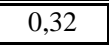 & 0,14 & 0,28 & (0,09 & 3 \\
\hline Wheat bran & 172 & 13,0 & 14,4 & 4,14 & 1,91 & 9,62 & 0,14 & 1,08 & 0,04 & 0,57 & 0,21 & 0,46 & 0,22 & 3,60 \\
\hline Wheat fodder flour & 257 & $\overline{12,0}$ & $\overline{14,2}$ & 3,00 & $\overline{0,93}$ & 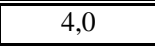 & 0,07 & 0,30 & 0,04 & 0,48 & 0,21 & $\overline{0,49}$ & 0,18 & 3,50 \\
\hline Sunflower meal, CP $40 \%$ & 228 & 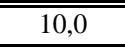 & 40,0 & 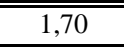 & 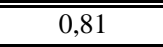 & 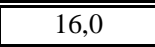 & 0,36 & 1,10 & 0,08 & 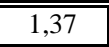 & 0,88 & $\overline{1,42}$ & 0,53 & 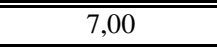 \\
\hline $\begin{array}{l}\text { Soybean meal, CP } 40 \% \\
\end{array}$ & 230 & $\begin{array}{l}, 0 \\
\end{array}$ & 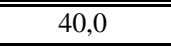 & 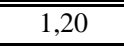 & $\overline{0,48}$ & 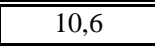 & 0,37 & 0,65 & 0,05 & 2,42 & 0,53 & 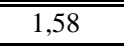 & 0,55 & 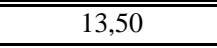 \\
\hline Sunflower press cake, CP $32 \%$ & 223 & 8,0 & (32,0 & 11,50 & $\overline{5,46}$ & 23,0 & 0,35 & 21,10 & 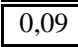 & 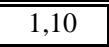 & 0,72 & 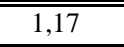 & 0,42 & 5,50 \\
\hline Soybean press cake, CP $36 \%$ & 260 & $\overline{9,0}$ & 36,0 & 5,80 & 2,62 & 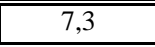 & $0,0,34$ & 0,65 & 0,05 & 2,20 & $0,0,47$ & 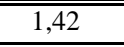 & $0,0,51$ & 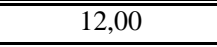 \\
\hline Alfalfa herb flour, CP $17 \%$ & 12120 & $\overline{\overline{10,0}}$ & 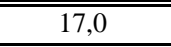 & 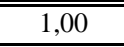 & 0,10 & 22,0 & $0,9,90$ & 0,26 & 0,07 & 0,74 & 0,26 & 0,67 & 0,24 & 3,50 \\
\hline Meat meal, CP $56 \%$ & 255 & 8,0 & 56,0 & 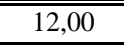 & 0,90 & \begin{tabular}{c|}
0 \\
\end{tabular} & 5,30 & 2,52 & 1,42 & 2,87 & 0,80 & 2,11 & 0,45 & 8,50 \\
\hline Non-fat bone meal, CP $35 \%$ & 146 & 10,0 & 35,0 & 7,20 & 0,06 & 0 & 13,15 & 7,59 & 1,94 & 0,24 & 0,04 & 0,06 & 0,02 & 5,20 \\
\hline $\begin{array}{l}\text { Fish meal, CP } 67 \% \text { \% } \\
\end{array}$ & $\overline{2303}$ & $8,8,0$ & 67,0 & 7,40 & 0,10 & 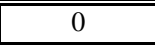 & 4,26 & 2,58 & $\begin{array}{ll}1,00 \\
\end{array}$ & 4,82 & $\overline{1,78}$ & 2,64 & 0,70 & 23,00 \\
\hline Meat and bone meal, CP $44 \%$ & 210 & 9,0 & $\begin{array}{l}44,0 \\
\end{array}$ & 12,50 & 0,52 & 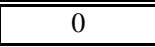 & $7 \overline{7,35}$ & 3,75 & 1,55 & $\begin{array}{ll}1,91 \\
\end{array}$ & 0,51 & 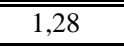 & 0,24 & $\begin{array}{ll}7,50 \\
\end{array}$ \\
\hline Blood meal, CP $80 \%$ & 280 & $\overline{10,0}$ & $\overline{80,0}$ & $\begin{array}{ll}1,00 \\
\end{array}$ & $\overline{0,10}$ & 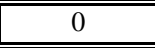 & 0,30 & 0,32 & 0,33 & 6,87 & $\begin{array}{ll}0,89 \\
\end{array}$ & 3,38 & 1,30 & $\begin{array}{ll}9,00 \\
\end{array}$ \\
\hline Corn gluten & 354 & 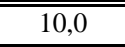 & 62,0 & (5,0 & 2,22 & (5,0 & 0,30 & $0,0,50$ & 0,02 & 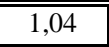 & 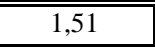 & 2,05 & 3 & 29,00 \\
\hline $\begin{array}{l}\text { Fodder yeast, } \mathrm{CP} 44 \% \\
\end{array}$ & 220 & $\begin{array}{l}9,0 \\
\end{array}$ & \begin{tabular}{l|l|}
44,0 \\
\end{tabular} & $\begin{array}{ll}1,50 \\
\end{array}$ & 0,06 & $\begin{array}{ll}1,40 \\
\end{array}$ & 0,52 & \begin{tabular}{|l|}
1,39 \\
\end{tabular} & 0,16 & 2,99 & 0,44 & 2,16 & 0,56 & 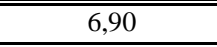 \\
\hline Sunflower oil & 853 & 0,2 & 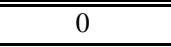 & 99,80 & 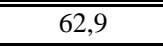 & 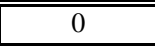 & $\begin{array}{l}0 \\
\end{array}$ & $\begin{array}{l}0 \\
\end{array}$ & 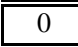 & $\begin{array}{l}0 \\
\end{array}$ & 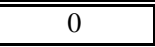 & 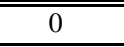 & 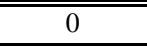 & 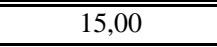 \\
\hline $\begin{array}{ll}\text { Salt } \\
\end{array}$ & $\begin{array}{l}0 \\
\end{array}$ & 3,0 & 0 & $\begin{array}{ll}0 \\
\end{array}$ & $\begin{array}{ll}0 \\
\end{array}$ & 0 & 0,50 & 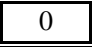 & 37,2 & 0 & 0 & 0 & 0 & $\begin{array}{ll}, 20 \\
\end{array}$ \\
\hline $\begin{array}{l}\text { Monocalcium phosphate } \\
\end{array}$ & 0 & 4,0 & 0 & 0 & 0 & 0 & 18,0 & 23,0 & $\begin{array}{ll}0 \\
\end{array}$ & 0 & 0 & 0 & 0 & 18,00 \\
\hline $\begin{array}{l}\text { Defluorinated phosphate } \\
\end{array}$ & 0 & 3,0 & 0 & 0 & 0 & 0 & 30,0 & 18,0 & 5,0 & 0 & 0 & 0 & 0 & 20,00 \\
\hline Limestone flour & 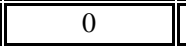 & 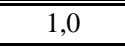 & 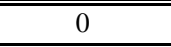 & 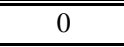 & 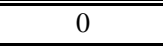 & 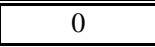 & 36,0 & 0,10 & 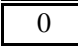 & 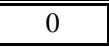 & 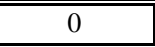 & 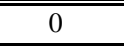 & 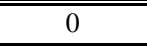 & 0,45 \\
\hline Feed chalk & 0 & 2,0 & 0 & 0 & 0 & 0 & 33,0 & \begin{tabular}{ll|l|}
0,18 \\
\end{tabular} & 0,30 & 0 & 0 & 0 & 0 & 1,10 \\
\hline Baking soda & 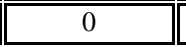 & 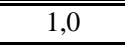 & $\overline{0}$ & 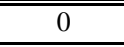 & $\overline{0}$ & $\overline{0}$ & 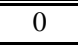 & 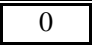 & 27,0 & 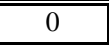 & $\overline{0}$ & $\overline{0}$ & $\overline{0}$ & 9,80 \\
\hline $\begin{array}{l}\text { Sodium sulfate anhydrous } \\
\end{array}$ & "0 & 3,0 & 0 & 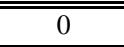 & 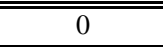 & 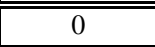 & "32,0 & "0 & 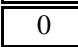 & "0 & 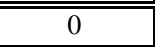 & 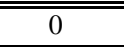 & 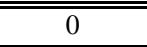 & 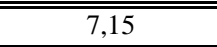 \\
\hline Monochlorohydrate lysine $98 \%$ & 399 & 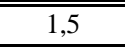 & 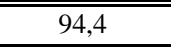 & 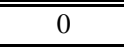 & 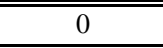 & 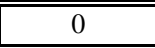 & 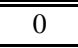 & 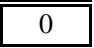 & 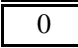 & 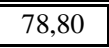 & 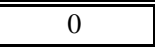 & 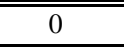 & 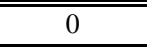 & 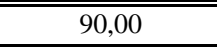 \\
\hline Lysine sulfate & 407 & 5,0 & 75,0 & 0 & 0 & 0 & 0 & $\begin{array}{ll}0 \\
\end{array}$ & 0 & 50,70 & 0,10 & 0,30 & 0,10 & 41,00 \\
\hline DL-methionine $98,5 \%$ & 502 & 0,2 & 58,1 & 0 & 0 & 0 & 0 & 0 & 0 & 0 & 98,5 & 0 & 0 & 110,00 \\
\hline L-tryptophan $98 \%$ & 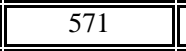 & 0,5 & $\begin{array}{lll}84,0 \\
\end{array}$ & 0 & 0 & 0 & $\overline{0}$ & 0 & 0 & $\begin{array}{ll}0 \\
\end{array}$ & 0 & 0 & 98,0 & $\begin{array}{l}83,75 \\
\end{array}$ \\
\hline Faizim XP 10000 & 268019 & $\overline{5,0}$ & 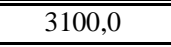 & $\overline{0}$ & 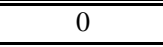 & $\overline{0}$ & 1400 & 1794 & 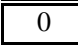 & 152,0 & 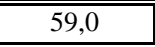 & $\overline{2121}$ & 42,0 & $\overline{100,00}$ \\
\hline Natufos E 10000 & 90100 & 5,0 & 3825,0 & 0 & 0 & 0 & 1950 & 1700 & 26,0 & 204,00 & 17,0 & 221 & 51,0 & 200,00 \\
\hline Premix for young geese $1-8$ weeks, $1 \%$ & 0 & 5,0 & 0 & 0 & 0 & 0 & 0 & 0 & 0 & 0 & 0 & 0 & 0 & 40,00 \\
\hline Premix for geese $9-26$ weeks, $1 \%$ & 0 & $\overline{5,0}$ & 0 & 0 & 0 & 0 & 0 & 0 & 0 & 0 & 0 & 0 & 0 & 35,00 \\
\hline Premix for adult geese, $1 \%$ & 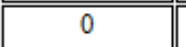 & 5,0 & $\overline{00}$ & 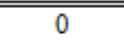 & 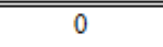 & $\overline{00}$ & 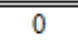 & 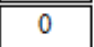 & 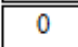 & 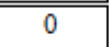 & 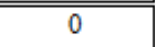 & 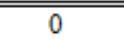 & 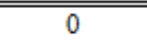 & 35,00 \\
\hline
\end{tabular}


Table 2 - Composition and nutritional value of the calculated compound feed recipes for geese

\begin{tabular}{|c|c|c|c|c|c|c|}
\hline \multirow{2}{*}{$\begin{array}{l}\text { Components and quality } \\
\text { indicators }\end{array}$} & \multicolumn{4}{|c|}{ Parent flock geese } & \multicolumn{2}{|c|}{ Broiler type geese } \\
\hline & $\begin{array}{c}\text { Starter } \\
0-3 \text { weeks } \\
\end{array}$ & $\begin{array}{c}\text { Grower } \\
\text { 4-8 weeks } \\
\end{array}$ & $\begin{array}{c}\text { Finisher } \\
\text { 9-26 weeks } \\
\end{array}$ & $\begin{array}{c}\text { Breeder from } \\
27 \text { week } \\
\end{array}$ & $\begin{array}{c}\text { Starter } \\
0-4 \text { weeks } \\
\end{array}$ & $\begin{array}{c}\text { Finisher } \\
\text { from } 5 \text { week } \\
\end{array}$ \\
\hline 1 & 2 & 3 & 4 & 5 & 6 & 7 \\
\hline Oats without husk & 4,0 & - & 6,0 & - & - & - \\
\hline Corn & 39,9 & 46,9 & 30,0 & 5,8 & 45,1 & 60,0 \\
\hline Rye & - & 5,0 & - & 7,0 & - & - \\
\hline Triticale & 5,0 & 10,0 & - & 30,0 & 5,0 & - \\
\hline Sorghum tannin $<0,5$ & 10,0 & - & 9,0 & 3,1 & 10,0 & 1,7 \\
\hline Wheat bran & - & 2,0 & 5,0 & 10,0 & - & - \\
\hline Wheat fodder flour & 10,0 & 8,0 & 15,0 & 15,0 & 10,0 & 10,0 \\
\hline Soybean meal, CP $40 \%$ & - & - & 2,0 & - & - & - \\
\hline Sunflower meal, CP $40 \%$ & 7,0 & - & - & - & 7,0 & 9,6 \\
\hline Soybean press cake, CP $36 \%$ & - & - & - & - & - & 11,0 \\
\hline Sunflower press cake, CP $32 \%$ & - & 9,0 & 15,0 & 15,0 & - & - \\
\hline Corn gluten & - & - & - & 0,1 & - & - \\
\hline Alfalfa herb flour, CP $17 \%$ & 3,0 & - & 10,0 & 2,9 & 3,0 & - \\
\hline Meat meal, CP $56 \%$ & 6,0 & 4,6 & - & - & 6,0 & - \\
\hline Non-fat bone meal, CP $35 \%$ & 2,3 & 4,0 & - & - & - & - \\
\hline Fish meal, CP $67 \%$ & 1,4 & - & - & - & 3,64 & - \\
\hline Meat and bone meal, CP $44 \%$ & 3,0 & - & - & - & 1,5 & - \\
\hline Blood meal, CP $80 \%$ & 2,7 & 2,8 & - & 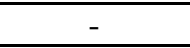 & 3,0 & - \\
\hline Sunflower oil & 0,6 & - & 1,2 & - & 0,77 & 0,8 \\
\hline Fodder yeast, CP $44 \%$ & 3,0 & 5,0 & 2,3 & 5,0 & 3,0 & 3,0 \\
\hline Monochlorohydrate lysine $98 \%$ & 0,10 & - & 0,19 & - & - & - \\
\hline Lysine sulfate & - & 0,07 & - & 0,12 & 0,03 & 0,49 \\
\hline DL-methionine $98,5 \%$ & 0,17 & 0,15 & 0,10 & 0,06 & 0,15 & 0,13 \\
\hline L-tryptophan $98 \%$ & 0,01 & - & - & - & - & - \\
\hline Salt & 0,18 & 0,30 & 0,30 & 0,30 & 0,29 & 0,30 \\
\hline Limestone flour & 0,64 & 1,17 & - & - & - & - \\
\hline Monocalcium phosphate & - & - & - & - & 0,52 & - \\
\hline Defluorinated phosphate & - & - & 1,6 & 1,42 & - & 1,76 \\
\hline Feed chalk & - & - & 1,1 & 2,98 & - & - \\
\hline Baking soda & - & - & 0,1 & 0,1 & - & 0,1 \\
\hline Sodium sulfate anhydrous & - & - & 0,1 & 0,1 & - & 0,1 \\
\hline $\begin{array}{l}\text { Premix for young geese } \\
1-8 \text { weeks, } 1 \%\end{array}$ & 1,0 & 1,0 & - & - & 1,0 & - \\
\hline Premix for geese $9-26$ weeks, $1 \%$ & - & - & 1,0 & - & - & - \\
\hline Premix for adult geese, $1 \%$ & - & - & - & 1,0 & - & 1,0 \\
\hline Natufos E 10000 & - & 0,01 & 0,01 & 0,01 & - & 0,01 \\
\hline Faizim XP 10000 & - & - & - & 0,01 & - & 0,01 \\
\hline Total & 100 & 100 & 100 & 100 & 100 & 100 \\
\hline Price of feed, UAH/t & 8792 & 7939 & 7832 & 6569 & 9244 & 9272 \\
\hline $\begin{array}{l}\text { Metabolizablek energy, } \\
\text { KCal/100 g }\end{array}$ & 282 & 286 & 266 & 251 & 290 & 311 \\
\hline \multicolumn{7}{|l|}{ The mass fraction, $\%$ : } \\
\hline crude protein & 20,27 & 18,85 & 15,92 & 16,93 & 20,41 & 16,76 \\
\hline $\mathrm{c} 18: 2 \omega 6$ & 1,54 & 1,61 & 2,56 & 1,53 & 1,67 & 2,06 \\
\hline crude fiber & 3,53 & 3,96 & 7,98 & 6,85 & 3,55 & 4,04 \\
\hline lysine & 1,00 & 0,90 & 0,75 & 0,72 & 1,00 & 0,94 \\
\hline methionine & 0,50 & 0,45 & 0,38 & 0,34 & 0,50 & 0,42 \\
\hline
\end{tabular}




\begin{tabular}{||l||c||c||c||c||c||c||}
\hline \multicolumn{1}{|c||}{1} & 2 & 3 & 4 & 5 & 6 & 7 \\
\hline \hline methionine + cystine & 0,78 & 0,72 & 0,65 & 0,63 & 0,78 & 0,69 \\
\hline \hline threonine & 0,71 & 0,68 & 0,59 & 0,61 & 0,75 & 0,62 \\
\hline \hline tryptophan & 0,22 & 0,20 & 0,20 & 0,21 & 0,22 & 0,19 \\
\hline \hline arginine & 1,21 & 1,13 & 0,97 & 1,00 & 1,16 & 1,00 \\
\hline \hline isoleucine & 0,67 & 0,62 & 0,63 & 0,66 & 0,70 & 0,67 \\
\hline \hline leucine & 1,62 & 1,49 & 1,23 & 1,15 & 1,71 & 1,43 \\
\hline \hline valine & 1,00 & 0,94 & 0,79 & 0,83 & 1,05 & 0,81 \\
\hline \hline histidine & 0,49 & 0,47 & 0,37 & 0,38 & 0,53 & 0,41 \\
\hline \hline phenylalanine & 0,88 & 0,83 & 0,73 & 0,74 & 0,92 & 0,77 \\
\hline \hline phenylalanine+tyrosine & 1,42 & 1,31 & 1,11 & 1,16 & 1,48 & 1,24 \\
\hline \hline glycine & 1,38 & 1,13 & - & - & 1,32 & - \\
\hline \hline calcium & 1,23 & 1,48 & 1,24 & 1,90 & 0,78 & 0,98 \\
\hline \hline phosphorus & 0,80 & 0,99 & 0,91 & 1,17 & 0,75 & 1,07 \\
\hline \hline shosphorus available & 0,58 & 0,70 & 0,57 & 0,76 & 0,55 & 0,73 \\
\hline \hline
\end{tabular}

Table 3 - Physical properties of compound feeds

\begin{tabular}{||l||c||c||c|c||c|c||c||c||}
\hline \multirow{2}{*}{\multicolumn{1}{|c||}{ Indicators }} & \multicolumn{2}{c||}{ Starter } & \multicolumn{2}{c||}{ Grower } & \multicolumn{2}{c||}{ Finisher } & \multicolumn{2}{c||}{ Breeder } \\
\cline { 2 - 9 } & $\begin{array}{c}\text { Experi- } \\
\text { mental }\end{array}$ & RTD & $\begin{array}{c}\text { Experi- } \\
\text { mental }\end{array}$ & RTD & $\begin{array}{c}\text { Experi- } \\
\text { mental }\end{array}$ & RTD & $\begin{array}{c}\text { Experi- } \\
\text { mental }\end{array}$ & RTD \\
\hline \hline Moisture content, $\%$ & 12,6 & 13,0 & 12,3 & 13,0 & 12,0 & 13,0 & 11,5 & 13,0 \\
\hline \hline $\begin{array}{l}\text { Angle of repose, } \\
\text { degree }\end{array}$ & 41 & $39-42$ & 41 & $39-42$ & 40,5 & $39-42$ & 39 & $39-42$ \\
\hline \hline Flowability, cm/s & 6,8 & $\mathrm{n} / \mathrm{n}^{*}$ & 6,9 & $\mathrm{n} / \mathrm{n}^{*}$ & 7,3 & $\mathrm{n} / \mathrm{n}^{*}$ & 7,4 & $\mathrm{n} / \mathrm{n}^{*}$ \\
\hline \hline Bulk density, $\mathrm{kg} / \mathrm{m}^{3}$ & 640 & $600-660$ & 625 & $600-660$ & 590 & $520-630$ & 562 & $520-630$ \\
\hline \hline
\end{tabular}

* - not normalized

Table 4 - Chemical and amino acid composition of feed for parent flock geese (based on dry matter)

\begin{tabular}{|c|c|c|c|c|}
\hline Nutrients & $\begin{array}{c}\text { Starter } \\
0-3 \text { weeks }\end{array}$ & $\begin{array}{c}\text { Grower } \\
\text { 4-8 weeks }\end{array}$ & $\begin{array}{c}\text { Finisher } \\
\text { 9-26 weeks }\end{array}$ & $\begin{array}{l}\text { Tribal period } \\
\text { from } 27 \text { week }\end{array}$ \\
\hline Dry matter, $\%$ & 878,40 & 878,70 & $\begin{array}{l}88,00 \\
\end{array}$ & 88,50 \\
\hline Crude protein, $\%$ & 23,20 & 21,50 & 18,10 & 19,13 \\
\hline Crude fat, $\%$ & 5,32 & 5,05 & 6,25 & 5,42 \\
\hline Crude fiber, $\%$ & 4,04 & 4,52 & 9,07 & 7,74 \\
\hline Calcium, mg\% & 1,41 & 1,69 & 1,41 & 2,15 \\
\hline Phosphorus, mg\% & 0,92 & 1,13 & 1,03 & 1,32 \\
\hline Lysine, \% & 1,14 & 1,03 & 0,85 & 0,81 \\
\hline Methionine + cystine, $\%$ & 0,89 & 0,82 & 0,74 & 0,71 \\
\hline Threonine, \% & 0,81 & 0,78 & 0,67 & 0,69 \\
\hline Tryptophan,\% & 0,25 & 0,23 & 0,23 & 0,24 \\
\hline
\end{tabular}

and feeding conditions;

$\checkmark$ ability to consume and digest a significant amount of fiber-rich feed with minimal consumption of concentrated feed;

$\checkmark \quad$ high ability to adapt to different climatic conditions;

$\checkmark \quad$ resistance to diseases;

$\checkmark \quad$ high growth rate of young animals - $4-5 \mathrm{~kg}$ at the age of 9 weeks;

$\checkmark \quad$ a wide range of products not only for the food industry (meat, fat, liver), but also for perfume, pharmaceutical, light [4 - 6].
The high-quality calculation of recipes is a necessary part of efficient production and use of finished products at the present stage of the feed industry development.

Optimization of compound feed recipes determines its composition and takes into account the impact of certain feed components on the physiology, health, growth and productivity of animals. Recipe calculation programs occupy a key place in the technological chain of animal husbandry production, combining producer and products consumer.

The quality of the final product and the compli- 
ance of the calculated indicators of nutritional value with the actual depend on the accuracy of the recipes calculation and take into account all the destabilizing factors in the technological production process. Thanks to modern software optimization of recipes, it becomes possible not only to make a diet with available raw materials that is optimal in quality and cost, but also to assess the feasibility of introducing a particular additive, both from a biological and economic point of view.

\section{Purpose and objectives of the analysis}

The aim of the study was to develop complete feed recipes for geese and determine their physical properties and chemical composition in comparison with regulatory and technical documentation. Standard methods of analysis were used for the research.

\section{Results and its discussion}

Geese must receive high quality and balanced feed by all indicators for the normal development and realization of genetic potential. Therefore, the urgent task is to develop recipes for high-quality geese feed using domestic available raw materials.

The following components were selected for the development of complete feed recipes for geese: corn, oats without husk, triticale, sorghum, rye, wheat bran, wheat fodder flour, soybean meal, sunflower meal, sunflower press cake, soybean press cake, alfalfa herb flour, meat meal, non-fat bone meal, fish meal, meat and bone meal, blood meal, corn gluten, fodder yeast, sunflower oil, salt, defluorinated phosphate, monocalcium phosphate, limestone flour, baking soda, feed chalk, sodium sulfate anhydrous, monochlorohydrate lysine, lysine sulfate, DL-methionine, L-tryptophan, faizim XP 10000, premixes $1 \%$, natufos E 10000 .

The nutritional value and cost of feed components are given in table 1.

With the help of the software package "Korm Optima Expert" [7] we have developed complete feed recipes for parent flock geese aged $0 \ldots 3$ weeks (starter), $4 \ldots 8$ weeks (grower), 9.. 26 weeks (finisher), older 27 weeks (breeder), and recipes for broiler type geese aged $0 \ldots 4$ weeks (starter) and older 5 weeks (finisher). The program includes the principle of calculating recipes at the minimum cost, taking into account the limitations of the input of each component and the nutritional value of the finished product using linear programming formulas.
The optimal composition of compound feed recipes for parent flock geese and broiler type geese at all stages of growth and productivity with a minimum cost was obtained with the help of the software package "Korm Optima Expert". They meet the feeding standards and the input restrictions of components and can be used for the geese full feeding (Table 2).

Experimental samples of starter, grower, finisher and breeder were made in accordance with the developed recipes of complete feed for parent flock geese. Recipes of compound feeds are given in table 2. Physical properties and chemical composition were studied in the experimental samples.

Study of physical properties.

Compound feeds were investigated according to the following indicators: moisture content, angle of repose, flowability and bulk density. The research results are given in table 3 .

As can be seen from the obtained data, experimental samples of starter, grower, finisher and breeder are characterized by satisfactory physical properties and comply with regulatory and technical documentation.

Study of chemical composition.

The fodder value of prepared compound feeds was evaluated based on the nomenclature of guaranteed feed quality indicators, taking into account the detailed norms of feeding geese on the following indicators: crude protein, crude fat, crude fiber, mass fraction of calcium, phosphorus, lysine, methionine + cystine, threonine, tryptophan.

Data on the study of chemical and amino acid composition of feed for parent flock geese are given in the table 4.

Data analysis of table 4 shows that the produced feeds are balanced in content of nutrients and biologically active substances and meets the physiological needs and feeding standards of the parent flock geese.

\section{Conclusions}

The optimal recipes of complete feeds for geese with a minimum price were calculated and experimental samples were made, based on theoretical and experimental research. The evaluation of quality indicators of compound feeds experimental samples determined that they meet the regulatory and technical documentation and feeding requirements.

\section{REFERENCES}

1. Volkova S. F. Rozvitok kombikormovoho virobnitstva yak osnova zabezpechennya prodovol choyi bezpeki Ukrayini / S. F. Volkova, K. O. Shcherbatova // Ekonomika kharchovoyi promislovosti. - 2015. - T. 2, vip. 26. - S. 13-17.

2. Hrihorenko O. Formuvannya kharchovikh ratsioniv naselennya / O. Hrihorenko // Tovari i rinki. - 2010. - T. 2, vip. 1. S. 118-124.

3. Eksportni horizonti YeS dlya nishevikh virobnikiv m'yasa ptitsi // Agravery.com [Veb-sayt]. - Odesa, 2020. - URL: https://agravery.com/uk/posts/show/eksportni-gorizonti-es-dla-nisevih-virobnikiv-masa-ptici (data zvernennya: 02.12.2020).

4. Rekomendatsiyi shchodo spryamovanoho viroshchuvannya, utrimannya i vidhodivli vodoplavnoyi ptitsi : dovidnik / I. I. Ivko [ta in.] / uklad. : I.I. Ivko, D.M. Mikityuk, V.O. Mel'nik, O.V. Ryabinina, N.I. Bratishko. - Birki: Birki, 2009. - 112 s.

5. Fedorovich Ye. I. Suchasniy stan ta perspektivi rozvitku husivnitstva Ukrayini / Ye. I. Fedorovich, V. S. Zaplatins`kiy // Naukoviy visnik LNUVMBT imeni S.Z. Izhits 'koho. - 2015. - T. 17, vip. 3. - S. 322-330.

6. Mel'nik V. A. Proizvodstvo produktsii vodoplavayushchey ptitsy v mire $i$ v Ukraine / V. A. Mel'nik // Institut zhivotnovodstva NAAN Ukrainy. - Odesa, 2020. - URL: http://ptitcevod.ru/produkciya-pticevodstva/proizvodstvoprodukcii-vodoplavayushhej-pticy-v-mire-i-v-ukraine.html (data obrashcheniya: 24.11.2020).

7. Software complex “Korm Optima Expert”, 2006. 
Н.В. Ворона, канд. техн. наук, доцент, E-mail: tarnin@te.net.ua А.В. Макаринська, канд. техн. наук, доцент, E-mail: allavm2015@gmail.com Кафедра технології комбікормів і біопалива Одеська національна академія харчових технологій, вул. Канатная, 112, м. Одеса, 65039, Україна

\title{
РОЗРОБКА РЕЦЕПТІВ КОМБІКОРМІВ ДЛЯ ГУСЕЙ ТА ВИЗНАЧЕННЯ ЇХ ЯКОСТІ
}

\begin{abstract}
Анотація
У статті зазначено, що гусівництво - важливе джерело збільшення виробництва м'яса птиці та розщирення асортименту продукиії птахівництва. В Украйні бізнес з розведення гусей є перспективним, прибутковим та недостатньо освоєним, з низькою конкуренцією. Рентабельність розведення гусей становить близько 75 \%. Крім того, гусівництво $\epsilon$ одним із можливих шляхів вирішення проблеми дефіцичту тваринного білка у світі.

На сучасному етапі розвитку комбікормової промисловості якісний розрахунок рецептів є необхідною частиною ефективного виробництва та використання готової продукиії.

Оптимізація рецептів комбікормової продукиії визначає ї̈ склад, а також враховує вплив певних кормових компонентів на фізіологію, здоров'я, показники зростання та продуктивності тварин. Програми розрахунку рецептів займають ключове місие в технологічному ланиюжку виробниитва тваринницького продукиії, поєднуючи виробника і споживача продукиії.
\end{abstract}

Якість кінцевої продукиії та відповідність розрахункових показників поживної иінності фактичним залежсть від точності розрахунку рецептів та врахування всіх дестабілізуючих факторів у технологічному процесі виробництва. Завдяки сучасним програмним комплексам оптимізації рецептів стає можливим з наявною сировиною не тільки скласти раціон, оптимальний за якістю і вартістю, але і оцінити доцільність введення тієї чи іншої добавки, як з біологічної, так $і$ з економічної точки зору.

Доведено, щңо гуси повинні отримувати якісний та збалансований за всіма показниками комбікорм для нормального розвитку та реалізації генетичного потенціалу. Тому актуальною задачею є розробка рецептів високоякісних комбікормів для гусей з використанням вітчизняної доступної сировини.

За допомогою програмного комплексу «Корм Оптіма Експерт» були розроблені рецепти повнораціонних комбікормів для гусей батьківського стада віком 0...3 тижні (стартер), 4..8 тижнів (гроуер), 9...26 тижнів (фінішер), та старше 27 тижнів (племінний), а також рецепти для гусенят-бройлерів віком 0...4 тижні (стартер) та старше 5 тижнів (фінімер). В програмі закладено принщи розрахунку рещептів за мінімальною собівартістю з урахуванням обмежень вводу кожного компоненту та поживності готового продукту за допомогою лінійного програмування за формулами.

У відповідності з розробленими рецептами повнораціонних комбікормів для гусей батьківського стада було виготовлено дослідні зразки стартового, гроуерного, фінішного комбікормів для молодняка та комбікорму племінного періоду. У дослідних зразках були вивчені фізичні властивості та хімічний склад. Встановлено, щэо дослідні зразки стартового, гроуерного, фінішного комбікормів та комбікорму племінного періоду характеризуються задовільними фізичними властивостями та відповідають нормативно - технічній документації, збалансовані за вмістом поживних та біологічно активних речовин, відповідають фізіологічним потребам та нормам годівлі гусей батьківського стада.

Ключові слова: комбікорми для гусей, фізичні властивості, хімічний склад, амінокислотний склад, показники поживної цінності.

1. Волкова С. Ф. Розвиток комбікормового виробництва як основа забезпечення продовольчої безпеки України / С. Ф. Волкова, К. О. Щербатова // Економіка харчової промисловості. - 2015. - Т. 2, вип. 26. - С. 13-17.

2. Григоренко О. Формування харчових раиіонів населення / О. Григоренко // Товари і ринки. - 2010. - T. 2, вип. 1. - С. 118124.

3. Експортні горизонти СС для нішевих виробників м'яса птиці // Agravery.com [Веб-сайт]. - Oдеса, 2020. - URL: https://agravery.com/uk/posts/show/eksportni-gorizonti-es-dla-nisevih-virobnikiv-masa-ptici (дата звернення: 02.12.2020).

4. Рекомендації щодо спрямованого вирощування, утримання і відгодівлі водоплавної птиці : довідник / I. I. Івко [та ін.] / уклад. : І.І. Івко, Д.М. Микитюк, В.О. Мельник, О.В. Рябініна, Н.І. Братишко. - Бірки: Бірки, 2009. - 112 с.

5. Федорович С. I. Сучасний стан та перспективи розвитку гусівництва Украӥни / Є. I. Федорович, В. С. Заплатинський // Науковий вісник ЛНУВМБТ імені С.3. Гжицького. - 2015. - Т. 17, вип. 3. - С. 322-330.

6. Мельник В. А. Производство продукиии водоплавающей птицы в мире и в Украине / В. А. Мельник // Институт животноводства НААН Украины. - Oдеса, 2020. - URL: http://ptitcevod.ru/produkciya-pticevodstva/proizvodstvo-produkciivodoplavayushhej-pticy-v-mire-i-v-ukraine.html (дата обращения: 24.11.2020).

7. Програмний комплекс «Корм Оптіма Експерт», 2006.

\section{Received 22.11.2020 \\ Reviewed 10.12.2020}

Revised 23.01.2021

Approved 30.03.2021

Cite as Vancouver Citation Style

Vorona N., Makarynska A. Development of compound feed recipes for geese and determination of their quality // Grain Products and Mixed Fodder's, 2021. 21. 1 (81).: 31-36. DOI https://doi.org/

Cite as State Standard of Ukraine 8302:2015

Development of compound feed recipes for geese and determination of their quality / Vorona N. et al. // Grain Products and Mixed Fodder's, 2021. Vol. 21. I. 1 (81). P. 31-36. DOI https://doi.org/ 